\title{
From knowledge acquisition to knowledge production: issues with Australian honours curricula
}

\author{
Catherine Manathunga ${ }^{\mathrm{a} *}$, Margaret Kiley ${ }^{\mathrm{b}}$, David Boud ${ }^{\mathrm{d}}$ and Robert Cantwell ${ }^{\mathrm{c}}$ \\ ${ }^{\mathrm{a}}$ TEDI, The University of Queensland, Brisbane, Australia; ${ }^{\mathrm{b}}$ CEDAM, The Australian National \\ University, Canberra, Australia; ${ }^{\mathrm{c}}$ Faculty of Education, University of Newcastle, Newcastle, \\ Australia; ${ }^{\mathrm{d}}$ UTS: Education, Sydney, Australia
}

(Received 9 December 2010; final version received 17 May 2011)

\begin{abstract}
Although there have been increasing attempts to involve undergraduate students in conducting research, a pivotal moment when students engage in knowledge production is during honours programmes. Honours programmes, particularly those in Australia, seek to develop students' capacity to engage in higher order thinking that may lead to knowledge production. This transition is facilitated through advanced disciplinary knowledge, research training and a research project. However, there is a pedagogical tension between requiring students to engage in this deeper level of inquiry at the same time as they complete a heavy knowledge acquisition load. This paper explores how a number of disciplines in Australia balance these elements of the honours curricula. It argues that the combination of these curriculum goals can make it difficult for students to apply the knowledge they have gained in advanced disciplinary and research training courses to their research project work. This has serious implications for honours programmes.
\end{abstract}

Keywords: honours; Australia; knowledge production; curricula

\section{Introduction}

The knowledge workers so desired by contemporary knowledge economies are increasingly required to apply knowledge to new issues, problems or contexts (Adler et al. 2000; Enders 2004; Jacob and Hellström 2000; Nerad and Heggelund 2008). As Russell, Wickson, and Carew (2008) neatly summarise, knowledge has become a commodity in the global market place that is expected to reform existing primary, manufacturing and service industries and create new industries and business ventures. As the numbers of people with access to education and information expand, knowledge is no longer the preserve of an elite few and research is no longer confined to universities. The effect of these changes has ensured that university graduates can no longer rely on claiming a special ability to acquire and critique existing knowledge. Employers now expect graduates to demonstrate a capacity to produce new knowledge. This agenda has, in turn, resulted in attempts to engage students more effectively in research from undergraduate degrees onwards (Brew 2010; Jenkins and Healy 2007; Seymour et al. 2004).

*Corresponding author. Email: catherine.manathunga@vuw.ac.nz 
While some undergraduate programmes have achieved success in involving undergraduate students in a range of research projects (Karukstis and Elgren 2007; Seymour et al. 2004), many do not take students beyond a basic awareness of research. It is not really until doctoral studies that students effectively begin to make substantial and original contributions to knowledge. However, the additional year-long type of Australian honours programmes mark a key transition in the transformation of graduates from knowledge acquirers to those who produce new knowledge. In particular, honours programmes typically expose students to the possibility of producing new knowledge and seek to develop their capacity to engage in this kind of knowledge production. There is normally scope within the programmes to undertake a more substantial investigative project than a project module in a basic undergraduate degree.

This paper seeks to explore how effectively the curriculum of honours programmes facilitates students' transition from knowledge acquisition to preparation for future knowledge production. Firstly, it maps the huge variation in honours programmes both between disciplines and across different countries in order to situate this study for an international audience. It then outlines the context and methodology adopted in this study of honours programmes in Australia. The transitions effected in honours programmes and the three most common models of the honours curriculum are then outlined. The paper then explores which features of these curricula are focused on knowledge acquisition, the problems in balancing knowledge acquisition and preparation for knowledge production, and the extent of preparation for knowledge production at honours levels.

\section{Honours - transplanted and adapted British models}

Before we can elaborate on this argument, it is necessary to review briefly the wide variation that exists in the types of honours programmes offered around the world. Generally speaking, honours programmes, as distinct from programmes awarded with honours, are mainly confined to former British colonies that inherited them along with other aspects of the British higher education system as it was in the late nineteenth and early twentieth centuries. Usually honours programmes were initially transplanted in these countries as an award of merit for high achievement in a threeyear undergraduate degree (Kiley et al. forthcoming). To this day, this model remains generally current in England, Wales, Ireland, Hong Kong, Malaysia, Singapore and some other countries. However, in Australia, New Zealand and South Africa in particular, this original model has been adapted to suit local cultural, educational and employment requirements.

In Australia, honours rapidly became primarily a pathway to postgraduate research and a way of building research cultures in Australian universities. Indeed, in the early days, an honours qualification was sufficient for academic jobs in Australian universities (Kiley et al. forthcoming). The primacy of the research pathway in honours was particularly the case where honours came to involve the completion of an additional year-long programme of research and, in some disciplines, advanced coursework (referred to in this paper as 'end-on' programmes). Developing either in parallel or during later periods, a range of professional fouryear undergraduate degrees qualifications, such as engineering, law and some health sciences, came to use honours in the more traditional English sense - as an 
undergraduate degree with merit. In New Zealand, a hybrid model of honours exists. In some universities, the traditional English model of honours as an award of merit in an undergraduate programme persists. In other New Zealand universities, the endon or additional year of research training and preparation model of honours is common. Meanwhile in South Africa, honours is usually an additional year of advanced study, but it is classified as a postgraduate degree and can be awarded separately or as the first year of a two-year master's degree (Bawa 2008).

Even within the UK, there is some variation. In Scotland, honours programmes in the sciences and the arts were generally four-year undergraduate programmes, which appear to be similar to Australian and New Zealand end-on honours models and which provided the model from which these were derived. Programmes are expected to 'exhibit a balance of breadth and depth' and may have 'a specific vocational focus and in some cases will carry recognition by an appropriate professional or statutory body'. In a small number of cases in Scotland, this degree is referred to as Master of Arts (Hons). As in Australia, New Zealand and South Africa, the Scottish honours degree is 'the recognised normal entry requirement to postgraduate study and to many professions' (QAA Scotland) (http://www.qaa. ac.uk/academicinfrastructure/fheq/scqf/scottishworkinggroup.asp).

While there are a huge variety of models of honours around the world, the one thing they have in common is the goal of assisting students to make the transition from knowledge acquirer to knowledge creator. Even in three-year undergraduate programmes where some students attain merit-based honours, such as those in England, there is some evidence that an honours result signals to universities and employers alike that this student has moved beyond a basic acquisition approach to learning. At the very least, they have demonstrated an ability to apply disciplinarybased knowledge to new settings, problems or situations. The Dearing Report (1997) emphasised this desire that higher education not only prepare students for work but also add 'to the world's store of knowledge and understanding... promoting the values that characterise higher education: respect for evidence; respect for individuals and their views; and the search for truth' (Summary, 2).

In a recent study of honours in Australia we mapped the provision of programmes named as honours degrees across disciplines in Australian universities (Kiley et al. forthcoming). We identified three essential curriculum components of honours programmes regardless of discipline. Each of these three components is designed to assist students to work towards making a shift from knowledge acquisition to knowledge production. The components are advanced disciplinary knowledge, research training and the completion of an independent research project. However, the weighting attached to each of these components varies according to the discipline or profession, as does the emphasis on the originality of the student's work at this level. So too, the various programmes studied also demonstrate variation in the extent of integration they offer between advanced coursework and the student's independent project or thesis.

\section{Methodology for our study}

This study focused on seven Australian universities representing each of the four university groupings, including the three self-determined formal groupings - the research-intensive Group of Eight (Go8), the Australian Technology Network of 
Universities (ATN) and the Innovative Research Universities (IRU) - and a group of universities which we have termed regional universities. We chose two universities from each of the first three groupings as they graduate almost $90 \%$ of research students in Australia and one university from the regional grouping. Given the nature of the universities, not all had the same range of disciplinary offerings. This was an interesting finding in itself, suggesting that there is a growing trend in universities to orient themselves to particular markets, for instance professional training or research training, and we found that this orientation was often mirrored in the types of honours programmes offered.

We selected six disciplines which offered different types of honours programmes:

- Physics and history were known to offer programmes generally aimed at preparing students for a higher research degree.

- Economics straddled both a professional and a research focus and is known to provide significant employment advantages.

- Psychology has a requirement that, for registration, successful completion of a fourth year of the undergraduate study that includes a focus on research skill development and achievement is required.

- Engineering honours is usually achieved within the ordinary degree time frame of four years.

- Environmental studies was selected as a multidisciplinary programme.

These areas were also selected to cover the classifications suggested by Becher (1989), which addresses the hard/soft/pure/applied characteristics of disciplines. They were present in most, although not all, of our research sites.

\section{Interviews and survey}

We undertook 45 semi-structured interviews with the designated convenor of the respective honours programme in each of our selected disciplines and research sites. Each interview took 30-60 minutes. The interviews were transcribed and returned to the interviewee for comment and any modification.

Another source of data came from 87 students responding to an online survey of the current honours students in the disciplines where interviews had been conducted (see http://www.aushons.anu.edu.au for a copy of survey). Through the survey we aimed to discover students' motivations for doing honours, how they were recruited, what teaching and learning aspects they valued, what their needs as honours students were, the extent to which they felt they were being supported and their career aspirations following completion of honours. Analyses were limited to descriptive statistics only. Given the limited size of the potential survey population as a result of our site and discipline-restricted approach as well as the workload current honours students were under when surveyed (September 2008) when they were finalising their thesis and preparing for examination in October, the response rate was within expectations. The survey was not intended to be representative of the population of honours students, but to illustrate students' views from the selected sites. 


\section{Research questions and data analysis}

The focus of this paper was to investigate the following research questions in relation to knowledge acquisition and production:

- How much knowledge production actually occurs at honours level in the programmes that we studied?

- Are all honours theses examples of knowledge production? How would you measure this?

- Should students be invited to see themselves as knowledge producers in all of the components of honours programme rather than only in the research project?

- Could this be facilitated more effectively by incorporating inquiry-based approaches to learning in advanced disciplinary knowledge and research training courses?

In order to trace the perceptions of honours coordinators and students about these issues, a content analysis of the honours coordinators' interviews and the openended students' responses was conducted. Indicative academics' and students' comments were selected to illustrate their views on how honours marks a transitional moment towards knowledge production, to identify issues in balancing knowledge acquisition and production in honours programmes and to raise discussion about how you might measure such honours knowledge production.

\section{Honours as transition}

The fact that honours acts as a transition point is clearly reflected in Shaw's categorisation of knowledge development (see Table 1) (Powell and McCauley 2003).

Our data analysis identified three key purposes for honours programmes, which are designed to facilitate honours students' transition from knowledge acquisition to knowledge production. These include the following:

- Advanced disciplinary knowledge - any form of disciplinary study in which the demands on students were greater than that of a 'pass' degree (may or may not involve additional coursework units).

- Research training - including research methodology, theory development or other material about research practice.

- Substantial independent research thesis or project - a project for which students take significant responsibility for planning and conducting, leading to an extended piece of work usually presented in the form of a thesis or dissertation (Issues Paper, http://www.aushons.anu.edu.au).

These key curriculum goals were widely endorsed by respondents to the Issues Paper. Clearly the first two curriculum features focus on additional knowledge acquisition, while it is generally in the research thesis or project that students take their first steps in creating new knowledge. 
Table 1. Knowledge development.

\begin{tabular}{|c|c|c|c|c|}
\hline $\begin{array}{l}\text { Senior high } \\
\text { school }\end{array}$ & Undergraduate & $\begin{array}{l}\text { Undergraduate } \\
\text { honours }\end{array}$ & Master's & Doctorate \\
\hline $\begin{array}{l}\text { knowledge } \\
\text { of the } \\
\text { underlying } \\
\text { concepts } \\
\text { and } \\
\text { principles } \\
\text { associated } \\
\text { with their } \\
\text { areas of } \\
\text { study, and } \\
\text { an ability to } \\
\text { evaluate } \\
\text { and } \\
\text { interpret } \\
\text { these within } \\
\text { the context } \\
\text { of that area } \\
\text { of study }\end{array}$ & $\begin{array}{l}\text { A critical } \\
\text { understanding of } \\
\text { the well- } \\
\text { established } \\
\text { principles of their } \\
\text { areas of study and } \\
\text { of the way in } \\
\text { which those } \\
\text { principles have } \\
\text { developed }\end{array}$ & $\begin{array}{l}\text { A systematic } \\
\text { understanding of } \\
\text { the key aspects of } \\
\text { their field of study, } \\
\text { including } \\
\text { acquisition of } \\
\text { coherent and } \\
\text { detailed } \\
\text { knowledge, at } \\
\text { least some of } \\
\text { which is at, or } \\
\text { informed by, the } \\
\text { forefront of the } \\
\text { defined aspects of } \\
\text { a discipline }\end{array}$ & $\begin{array}{l}\text { A systematic } \\
\text { understanding of } \\
\text { knowledge, and a } \\
\text { critical awareness } \\
\text { of current } \\
\text { problems and/or } \\
\text { new insights, } \\
\text { much of which is } \\
\text { at, or informed } \\
\text { by, the forefront } \\
\text { of their academic } \\
\text { discipline, field of } \\
\text { study or area of } \\
\text { professional } \\
\text { practice }\end{array}$ & $\begin{array}{l}\text { The original } \\
\text { creation and } \\
\text { interpretation of } \\
\text { new knowledge, } \\
\text { through original } \\
\text { research, or other } \\
\text { advanced } \\
\text { scholarship, of a } \\
\text { quality to satisfy } \\
\text { peer review, } \\
\text { extend the } \\
\text { forefront of the } \\
\text { discipline and } \\
\text { merit publication }\end{array}$ \\
\hline
\end{tabular}

Source: Adapted from Powell and McCauley (2003).

So already it is obvious that the balance of honours curricula is weighted more heavily towards knowledge acquisition. This is the result of a number of factors and varies greatly across different disciplines and fields of study. First of all, in many countries honours programmes are either part of four-year professional undergraduate degrees or still classed as undergraduate in the case of end-on programmes. As we can see from the categorisation above (Powell and McCauley 2003), honours is still very much regarded as a moment of transition between knowledge acquisition and knowledge production. It is really only the last segment of the categorisation of knowledge development that hints at preparation for higher order thinking and knowledge production - 'knowledge, at least some of which is at, or informed by, the forefront of the defined aspects of the discipline'.

The use of the metaphor 'stepping stone' in several interviews with honours coordinators emphasises honours as a moment of transition between knowledge acquisition and knowledge production (Interview 2, Physics, IRU, and Interview 12, Communication, ATN, pp. 1, 2 and 6). For example, an honours coordinator in Physics argued that the honours thesis was:

a stepping stone from undergraduate study into the world of research ... [where students are taught] to ask the right questions and test the right things under close supervision. (Interview 2, Physics, IRU, p. 2)

Other metaphors, such as 'students in the four-year programme are only dipping their toe in the water', also emphasise honours as transitional (Interview 11, Engineering, ATN, p. 1). It was also at this turning point in a student's education that academics could: 
differentiate the students that only follow recipes ... and those students [who] are able to stand on their own feet and able to think for themselves. (Interview 13, Physics, IRU, p. 4)

Secondly, in some fields, in earlier parts of the four-year undergraduate programme or in the three-year pass degree, there has been an explosion in content deemed necessary to cover. In other cases, more in-depth theoretical training occurs at honours level compared with undergraduate for example. For a variety of pedagogical and financial reasons, the earlier years of study may also have experienced a rationalisation of course content in some disciplines. This has ensured that more and more content knowledge that is regarded as essential to a profession or to undertaking further research has been pushed up into the fourth year of the programme. For example, several engineering honours coordinators highlighted the development of the field over the last 40 years and how they had to:

squeeze all that in with all the other fundamentals ...there is no way I can pack that stuff in the remaining 13 weeks. (Interview 6, Engineering, IRU, pp. 4 and 5)

A similar result was found by Kiley, Moyes, and Clayton (2009), where there were reports in the experimental sciences of 'bench work' being too expensive for extensive use in the first three years with large classes and has been located increasingly in the honours year.

In other areas, there was limited space in undergraduate programmes for adequate theoretical training. For example, in the five history programmes included in this study, the focus was often on more in-depth theoretical training as well as advanced disciplinary knowledge. These courses, which were not always compulsory, were run at all of the universities included in this research. Similar patterns were evident in the two English/communication studies honours programmes included in this research, although at one IRU methodologies tended to be taught within the content courses rather than as a separate course (Interview 1, IRU, p. 1).

Interestingly, some students felt that they actually needed more content knowledge to be included in their undergraduate programme so that they would be sufficiently prepared for honours and knowledge production. One student responded in the student survey by saying that 'it would have been desirable to have acquired a broader knowledge of my field in undergrad before embarking on the fairly high level research involved in honours' (Student survey, open-ended question, p. 4).

Thirdly, in some of the professional fields, a disproportionate emphasis is placed on advanced disciplinary knowledge compared with research training and the independent research project. This ensures that the curriculum balance is thrown even more to the side of knowledge acquisition. The priority appears to be that graduates should be more immediately work-ready in the sense of being able to practise effectively rather than generating new knowledge in a practice area, which, it is conventionally assumed, comes after developing a good knowledge of practice. This could eventually be a problem, however, as more and more employers outside the university sector expect honours graduates to be adept at knowledge production as well as acquisition.

For the embedded honours programmes in engineering contained in this study, the goal of advanced disciplinary knowledge and achievement was the primary purpose of the award of honours. While they all incorporated the production of a 
substantial independent research thesis or project often undertaken in a group setting, this project was designed to assess students in their ability to apply this advanced disciplinary knowledge and to prepare them for the types of problemsolving that typically take place within professional practice. There was a similar emphasis in honours programmes in psychology, computer science and IT and economics. In spite of the fact that psychology honours coordinators highlighted the importance of research and knowledge production in clinical as well as in academic psychology practice, the goals of these programmes do appear to substantially favour knowledge acquisition over knowledge production, perhaps because of the very strong expectation in that discipline that students will necessarily need postgraduate study as a prerequisite to enter the profession.

\section{Problems balancing knowledge acquisition and production}

In some cases, the focus on knowledge acquisition during honours can be experienced as highly distracting for students who are keen to engage in their research project. For example, one student suggested that 'my honours course contains too much coursework (irrelevant to my research topic) so that I am not able to sufficiently focus on my research project' (Student survey, open-ended question, $p$. 2). Another student argued that universities should 'offer courses focussed more on subjects related to thesis topics' (Student survey, open-ended question, p. 3). Generally students advocated greater compatibility between the coursework and their thesis topics and emphasised that the timing of coursework assessment directly interfered with their thesis work - 'assessment for coursework has not considered due dates for the thesis (i.e. having an assignment due two days before thesis submission)' (Student survey, open-ended question, p. 4). This was certainly not conducive to facilitating the shift towards knowledge production and often caused students to 'neglect their other units because they need to put more time into their project' (Student survey, open-ended question, p. 4).

The sense of honours as a high pressured and, at times brutal, preparation for the world of knowledge production came through clearly in the student survey. As one student suggested, the 'extremely heavy workload is not enjoyable (surprise, surprise)' (Student survey, open-ended question, p. 3). This time intensity is particularly problematic at a time when students are starting to grapple with knowledge production for the first time.

Most honours coordinators in this study seemed to be unaware of the problems students experience in trying to balance the knowledge acquisition and preparation for knowledge production features of the honours curriculum. Indeed, some saw the inclusion of additional coursework at this level as broadening (Interview 13, Physics, IRU). Only one honours coordinator in psychology acknowledged the intensity of the honours programme and argued that 'the honours year is the hardest year... [The PhD] is just more spread out, the workload is a bit more manageable' (Interview 29, Psychology, Regional, p. 4). Often there are incompatible sequences of study as well where students must design their projects well before the advanced knowledge courses are completed, which ensures that they are unlikely to influence much of the research project.

Shaw (2010) in her cross-disciplinary honours study found that those involved in end-on programmes perceived that coursework had a positive impact on their 
research while those in embedded honours programmes experienced it as negative. In an earlier study (Kiley, Moyes, and Clayton 2009) the change in the honours curriculum, particularly as reflected in assessment, was evidenced by an increase in the number of 'assessable components'. For example, rather than the simple thesis and coursework we have three parts: research project dossier and thesis $(60 \%)$, 'additional' work (30\%) and a seminar (10\%). However, these components include a sophisticated combination of formative and summative research skill development and research output (Kiley, Moyes, and Clayton 2009).

\section{Preparing for knowledge production at honours level}

Our data and other studies (see, for example, Zeegers and Barron 2009) indicate that knowledge production takes very different forms in honours programmes across the disciplines. If we took publication as a measure of knowledge production, then it would certainly appear that engineering honours theses were more about the acquisition and application of knowledge. In other fields, publication of honours research was common. For example, in environmental science, one honours coordinator indicated that it is not unusual for an Honours student to produce two publications and even three' (Interview 10, Environmental Science, ATN, p. 1). Publishing honours research was also mentioned by several honours coordinators in physics and economics. In multimedia communication and the creative arts, students may produce saleable digital animation or publishable collections of short stories and poetry, which could be argued to fit the category of knowledge production (Interview 12, Communication, ATN, p. 2). It is also possible that an award of first class honours may suggest a higher degree of knowledge production than knowledge acquisition. For example, one economics honours coordinator spoke about first class honours students as producing a thesis 'which is essentially publishable in a decent journal' (Interview 38, Economics, Go8, p. 5).

Another possible measure of knowledge production is encapsulated in Powell and McCauley's (2003) definition of honours research that is at or informed by the forefront of the ... discipline'. For one history honours coordinator, this was how she or he saw honours research - 'I want to get a sense of the next cutting edge of the discipline' (Interview 17, History, IRU, p. 3). She or he described honours as the opportunity to 'generate new research' (Interview 17, History, IRU, p. 6).

The degree of originality and creativity expected at honours level could also be a measure of the extent to which honours research is about knowledge production. In history, IT and physics, quite a degree of emphasis was placed upon originality. For example, one honours convenor argued that 'it's meant to be original research, a contribution to historical knowledge' (Interview 4, History, IRU, p. 1).

Furthermore, the absence of formal coursework may signal a focus on knowledge production. For example, in one health science honours programme at an IRU, no formal coursework was required and instead students completed a literature review, a seminar presentation, a thesis and a thesis defence. It was expected that students had already been 'exposed to the theory of research methods in the 3 years of the undergraduate degree' (Interview 7, Health Science, IRU, p. 3). This is the approach more typical of many of the traditional sciences where the additional honours year focuses only on the completion of an honours thesis project (with some assessment also involving oral presentations of the honours work). 


\section{Integration between honours coursework and research}

We suggest that facilitating honours students' transitions from knowledge acquisition to knowledge production might be more effectively achieved by providing a greater level of integration between their coursework and individual research. Although this does occur in some programmes, it is still not a regular feature of most honours programmes. Such integration has already been studied as a means for achieving more effective learning outcomes in professional doctorate programmes (Manathunga, Smith, and Bath 2004). For example, in some professional doctorate programmes, some of the advanced disciplinary and research training courses are 'designed to feed directly into the research component through required tasks such as a research proposal or literature review' (Manathunga, Smith, and Bath 2004, 241). There was evidence in our data that some of the programmes we studied offered varying levels of integration between honours coursework and research. This was also something students advocated very strongly (Student survey, open-ended responses).

The most common integrated pattern that was evident in the honours programmes included in this study was where research skills, methods or theoretical courses involved assessment that required students to apply their skills directly to their research projects. This was the form of integration most likely to assist students in making the transition from knowledge acquisition to knowledge production. In English, history, health science and IT honours programmes, students wrote a literature review essay in one unit of coursework. In several cases, this essay became a chapter of students' theses. For example, in an IT honours programme at an IRU, 'Research Methods... would eventually result in a chapter in the thesis, for the foundation of the thesis and the methodology, the philosophical approach [and]... Directed Readings... would also result in a chapter within the thesis' (Interview 24, IRU, p. 1). These are examples of the 'preparation/development' form of integration identified by Manathunga, Smith, and Bath (2004, 243), where 'coursework [acts] as preparation for the research/thesis component as well as courses running in parallel that feed into the thesis component'.

The honours programmes we studied also included some 'preparation/progress' forms of integration identified by Manathunga, Smith, and Bath (2004, 243), which involved a 'preparation phase along with a progress phase running in parallel where students are required to take part in courses...to check progress and provide feedback'. These mainly took the form of presentations on their progress with their individual research projects (for example, Interview 4, History, IRU, p. 2). Again this type of assessment provided students with feedback on their efforts to produce new knowledge in addition to that received within supervision. There were also some programmes in this study, such as psychology (Interview 3, IRU, p. 1), where there was no formal integration. Instead students were required to integrate their understandings of theory and methodology gained from specific coursework to their thesis research on their own. This is likely to be the least effective means of facilitating students' transitions to knowledge production.

\section{Conclusions}

This research has significant implications for the design and implementation of future honours curricula, the design and implementation of undergraduate 
programmes or courses placed earlier in the embedded honours programmes, and the role honours convenors and supervisors play in facilitating students' transition to knowledge production. Firstly, our research highlights the need to redesign the honours curricula in many disciplines to more explicitly support students' transition to knowledge production. There are strong indications in our data that suggest that this could partly be achieved by establishing through curriculum design and assessment more integration between the coursework students complete in order to build advanced disciplinary knowledge and understandings of theory and methodology and their individual research. This type of integration has already been shown to enhance student learning in professional doctorate programmes (Manathunga, Smith, and Bath 2004) and it is far more likely to facilitate more effectively students' preparation for knowledge production than relying on students to process these links on their own. Adopting an inquiry-based pedagogical approach in advanced disciplinary and research training courses could also build knowledge production skills more effectively than traditional didactic pedagogies.

Indeed, aiming for a form of constructive alignment between the three components of honours programmes to ensure that they mutually supported each other and were not seen as separate and distinct would be an important innovation in honours curricula. While we have seen increasing alignment between the research skills component and the thesis, we also need to see new forms of alignment with the advanced disciplinary knowledge courses. At this stage, some programmes have sequenced these courses in ways that they can never connect with the research project. It may be more effective to structure advanced knowledge courses as intensive modules that are completed before project planning even starts.

There may also be a need to consider reducing the amount and type of coursework and assessment students are required to complete in honours or, at least, to ensure due dates for this assessment to enable useful feedback to be given during the project phase and take account of thesis deadlines. Rethinking the type of coursework and assessment would also be important to allow greater space and time to assist students to make the transition to knowledge production. Overloading students inhibits the possibility of them taking up deep approaches to what they are doing and new subject positions as knowledge producers. A possible alternative that at least one Australian university is considering is to phase out one year end-on honours programmes in favour of longer master's coursework programmes to allow students a longer time period in which to make the transition from knowledge acquisition to knowledge production. This could also bring Australian programmes into greater alignment with the Bologna model.

Regardless of which option is adopted, this will have implications for the design and implementation of undergraduate programmes as a whole. There may be a need in some disciplines to ensure that more advanced disciplinary content is taught in these programmes instead of relying on honours to do the job. If this is not possible in some disciplines, then moving towards a master's programme and phasing out honours programmes may be the most effective courses of action.

None of these changes to honours curricula can be achieved without an increase in a general awareness of the importance of facilitating students' transition from knowledge acquisition to knowledge production. It was clear from our research that the majority of honours convenors seemed unaware of the difficulties caused by overloading the honours curricula with knowledge acquisition at a time when 
students were trying to grapple with knowledge production for the first time. Although they articulated an awareness of honours as a transitional moment, it would improve students' experiences of honours programmes if honours convenors were encouraged to really think through the relative weighting attached in their programmes to knowledge acquisition and knowledge production and how they might more effectively facilitate students' movement towards knowledge production.

So too, additional studies of honours supervisors need to be conducted to understand more about their role in facilitating students' shift towards knowledge production and the particular pedagogical strategies they adopt towards this curriculum goal. There has been very little research on supervision at honours level, and the honours convenors included in this study did not really engage with pedagogical and supervision questions even when prompted to do so.

Therefore, there needs to be significant reform of the honours curriculum in order to more effectively facilitate students' transition from knowledge acquisition to knowledge production if we are to prepare them adequately for enrolment in research higher degrees or for participation in a knowledge economy that is increasingly expecting graduates to be able to reform existing industries and create new industries and business ventures.

\section{Acknowledgements}

The authors acknowledge the ALTC and Ida Nursoo, Merrilyn Pike and Anicca Main.

\section{References}

Adler, N., T. Hellström, M. Jacob, and F. Norrgren. 2000. A model for the institutionalization of university-industry partnerships. In The future of knowledge production in the academy, ed. M. Jacob and T. Hellström. 125-38. Buckingham: SRHE and Open University Press.

Bawa, A. 2008. South Africa. In Toward a global PhD? Forces and forms in doctoral education worldwide, ed. M. Neradand M. Heggelund, 117-30. Seattle: University of Washington.

Becher, T. 1989. Academic tribes and territories. Milton Keynes, UK: SRHE and Open University Press.

Brew, A. 2010. Imperatives and challenges in integrating teaching and research. Higher Education Research and Development 29, no. 2: 139-50.

Dearing Report. 1997. Higher education in the learning society. London: Westminster.

Enders, J. 2004. Research training and careers in transition: A European perspective on the many faces of the Ph.D. Studies in Continuing Education 26, no. 3: 419-29.

Jacob, M., and T. Hellström. 2000. The future of knowledge production in the academy. Buckingham: SRHE and Open University Press.

Jenkins, A., and M. Healey. 2007. Critiquing excellence: Undergraduate research for all students. In International perspectives on teaching excellence in higher education, ed. A. Skelton, 117-32. London: Routledge.

Karukstis, K., and T. Elgren. 2007. How to design, implement, and sustain a research-supportive undergraduate curriculum. Washington, DC: Council on Undergraduate Research. http:// www.cur.org/publications/compendium.html (accessed 14 May 2009).

Kiley, M., D. Boud, R. Cantwell, and C. Manathunga. Forthcoming. Honouring the incomparable: Honours in Australian universities. Higher Education.

Kiley, M., T. Moyes, and P. Clayton. 2009. 'To develop research skills': Honours programs for the changing research agenda in Australian universities. Innovations in Education and Teaching International 46, no. 1: 15-25. 
Manathunga, C., C. Smith, and D. Bath. 2004. Developing authentic integration between research and coursework in professional doctoral programs. Teaching in Higher Education 9, no. 2: 235-46.

Nerad, M., and M. Heggelund. 2008. Toward a global PhD? Forces and forms in doctoral education worldwide. Seattle: University of Washington.

Powell, S., and C. McCauley. 2003. The process of examining research degrees: Some issues of quality. Quality Assurance in Education 11, no. 2: 73-83.

QAA Scotland. 2006. Verification of the compatibility of framework for qualifications in higher education institutions in Scotland. http://www.qaa.ac.uk/academicinfrastructure/ fheq/scqf/scottishworkinggroup.asp (accessed 14 May 2009).

Russell, A., F. Wickson, and A. Carew. 2008. Transdisciplinarity: Context, contradictions and capacity. Futures 40: 460-72.

Seymour, E., A.B. Hunter, S.L. Laursen, and T. Deantoni. 2004. Establishing the benefits of research experiences for undergraduates in the sciences: First findings from a three-year study. Science Education 88, no. 4: 493-534.

Shaw, K. 2010. Student experience of undergraduate research projects. Unpublished doctoral thesis, University of Newcastle.

Zeegers, M., and D. Barron. 2009. Honours: A taken-for-granted pathway to research? Higher Education 57, no. 5: 567-75. 
This article was downloaded by: [University of Technology Sydney]

On: 02 May 2013, At: 20:08

Publisher: Routledge

Informa Ltd Registered in England and Wales Registered Number: 1072954 Registered

office: Mortimer House, 37-41 Mortimer Street, London W1T 3J H, UK

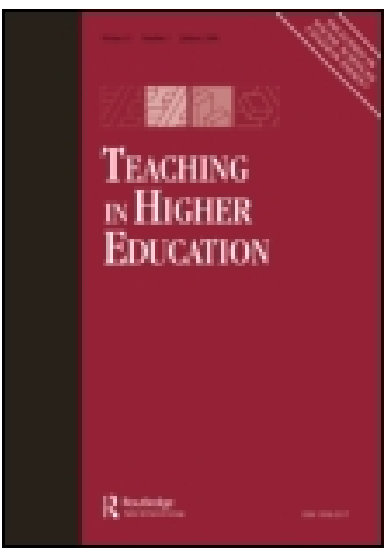

\title{
Teaching in Higher Education
}

Publication details, including instructions for authors and subscription information:

http:// www.tandfonline.com/loi/ cthe20

\section{From knowledge acquisition to knowledge production: issues with Australian honours curricula}

\author{
Catherine Manathunga ${ }^{a}$, Margaret Kiley ${ }^{b}$, David Boud ${ }^{d} \&$ Robert \\ Cantwell ${ }^{\mathrm{C}}$ \\ a TEDI, The University of Queensland, Brisbane, Australia \\ ${ }^{b}$ CEDAM, The Australian National University, Canberra, Australia \\ ${ }^{c}$ Faculty of Education, University of Newcastle, Newcastle, \\ Australia \\ d UTS: Education, Sydney, Australia \\ Published online: 15 J un 2011.
}

To cite this article: Catherine Manathunga , Margaret Kiley, David Boud \& Robert Cantwell (2012): From knowledge acquisition to knowledge production: issues with Australian honours curricula, Teaching in Higher Education, 17:2, 139-151

To link to this article: http:// dx.doi.org/ 10.1080/ 13562517.2011.590981

\section{PLEASE SCROLL DOWN FOR ARTICLE}

Full terms and conditions of use: http://www.tandfonline.com/page/terms-andconditions

This article may be used for research, teaching, and private study purposes. Any substantial or systematic reproduction, redistribution, reselling, loan, sub-licensing, systematic supply, or distribution in any form to anyone is expressly forbidden.

The publisher does not give any warranty express or implied or make any representation that the contents will be complete or accurate or up to date. The accuracy of any instructions, formulae, and drug doses should be independently verified with primary sources. The publisher shall not be liable for any loss, actions, claims, proceedings, demand, or costs or damages whatsoever or howsoever caused arising directly or indirectly in connection with or arising out of the use of this material. 